The Tolstoy Defence, 2018) kreivi Leo Tolstoilta pyydetään apua syylliseksi lavastetun sotilaan puolustamisessa. Toiseen maailmansotaan sijoittuvat Puolan kuolemanleiristä kertova humaani Sobibor (2018, ohj. Konstantin Habenski) ja lapsen silmin nähty Anna's War (Voina Anny, 2018, ohj. Aleksei Fedortšenko). Kantemir Balagovin palkittu esikoisohjaus Closeness (Tesnota, "Läheisyys", 2017) on kitkerä kuvaus nuoren naisen ratkaisusta mahdottomassa tilanteessa. Tarjolla oli myös Eduard Novikovin jakuutinkielinen The Lord Eagle (Toyon kyyl, 2018) ja tataarinkielinen Mullah (2018), jonka esityksen jälkeen Jukka Mallinen haastatteli Tatarkinon johtajatarta Miljaguša Aituganova Ljabibovnaa. Festivaalin päätöselokuvana nähtiin palkittu Core of the World (Serdtse mira, 2018). Se kertoo erämaassa asuvasta eläinlääkäristä, joka ymmärtää paremmin eläimiä kuin ihmisiä. Elokuvan käsikirjoittaja ja ohjaaja Natalija Meštšaninova ja hänen näyttelijämiehensä, pääroolin tehnyt
Stepan Devonin tavattiin festivaalin päättäneessä keskustelussa, jossa heitä haastatteli Velipekka Makkonen. Vuoden 2019 uutena kategoriana esitettiin valikoima venäläisiä lyhytelokuvia, valitettavasti myös yksi tekijänsä viimeiseksi työksi jäänyt: Armenian vallankumouksesta kertovan dokumentin Viimeinen päivä (Posledni den, 2018) tehnyt Aleksandr Rastorgujev (19712018) sai surmansa viime vuonna työtehtävissä Keski-Afrikan tasavallassa.

Kino Lokakuu järjestettiin tutuksi tulleessa Andorrassa ja Dubrovnikissa nyt viimeisen kerran: alkukesästä remonttiin menevä Rakennusmestarien talo muutetaan hotelliksi ja historiaan jäävät myös legendaariset baarit Corona ja Kafe Moskova. Epäilemättä korvaava paikka festivaalille löytyy, ja venäläisen elokuvan uudet tuulet pääsevät puhaltamaan meillä myös ensi vuonna.

\section{Mia Öhman}

\title{
Konstruktivismia Moskovan kaduilla
}

Kiinnostus varhaisen Neuvostoliiton konstruktivistiseen arkkitehtuuriin on viime vuosina lisääntynyt niin Venäjällä kuin ulkomaillakin. Neuvostoliiton 1920-luvun kirjalliset ja kuvataiteelliset kokeilut ovat yleisesti tunnettuja, ja arkkitehtuuristakin tiedetään utopistisimmat ja usein toteuttamatta jääneet kohteet, kuten Kolmannen internationaalin muistomerkki eli niin sanottu Tatlinin torni. Nyt huomiota ovat kuitenkin saaneet myös arkisemmat rakennukset. Tällaisia ovat esimerkiksi Pietarin Traktornaja ulitsan pienkerrostalot, jotka Narvan aukion tuntumassa muodostavat yhtenäisen puutarhakorttelin avarine sisäpihoineen.

Konstruktivistisen rakentamisen keskus oli kuitenkin itseoikeutetusti 1920-luvulla uusi pääkaupunki Moskova, ja sinne ehtikin nousta eniten tyylisuuntaa edustavia rakennuksia. Konstruktivismin tavoitteena oli hyödyntää uusinta rakennustekniikkaa ja -taitoa ihmisten hyvinvoinnin edistämiseksi. Aineellisesti ahtaissa oloissa liike joutui myös turvautumaan luoviin ratkaisuihin. Nykynäkökulmasta oudonkin näköiset talot eivät tavoitelleet taiteellista erikoisuutta sinänsä, vaan toimivat uutta elämää luomaan pyrkineen tyylisuunnan lippulaivoina. Stalinin kaudella 1930-luvulla konstruktivismi koki maineenmenetyksen ja korvautui pompöösillä stalinistisella klassismilla pylväineen kaikkineen. Tyylisuunta ei enää neuvostoaikana koskaan kunnolla elpynyt, ja monet 1920-luvulla rakennetut kohteet ehtivät rapistua tai kadota kokonaan.

Viime vuosina konstruktivistinen arkkitehtuuri on kuitenkin kokenut pienen renessanssin. Alkuperäisiä kohteita pyritään restauroimaan tai ainakin ne halutaan asettaa suojelun alaisiksi, jolloin niiden purkaminen uudisrakentamisen tieltä estettäisiin. Osa suojelutoimista on yksityisten tahojen aikaansaamia, toisissa on mukana myös Venäjän valtio. Muutamat uudet arkkitehtitoimistot ovat jopa ottaneet konstruktivismin yhdeksi suunnannäyttäjäkseen uusien rakennusten suunnittelussa. Moskovalaisen valokuvaaja Natalia Melikovan perustama The Constructivist Project -sivusto (theconstructivistproject.com) tuo esiin Neuvostoliiton konstruktivistisen arkkitehtuurin historiaa ja sen perintöä uudella Venäjällä. Sivusto ylläpitää myös tietokantaa rakennuksista.

Moskovan arkkitehtuurista kiinnostuneille on julkaistu myös kartta Konstruktivistskaja karta Moskvy, jonka avulla löytää viisikymmentä säilynyttä ja tutustumisen arvoista konstruktivismin helmeä. Tässä kuvaesseessä esitellään joitain näistä tunnetuimmista rakennuksista. Valokuvat ovat jutun tekijän maaliskuussa 2019 ottamia.

Teksti ja kuvat: Ville-Juhani Sutinen 


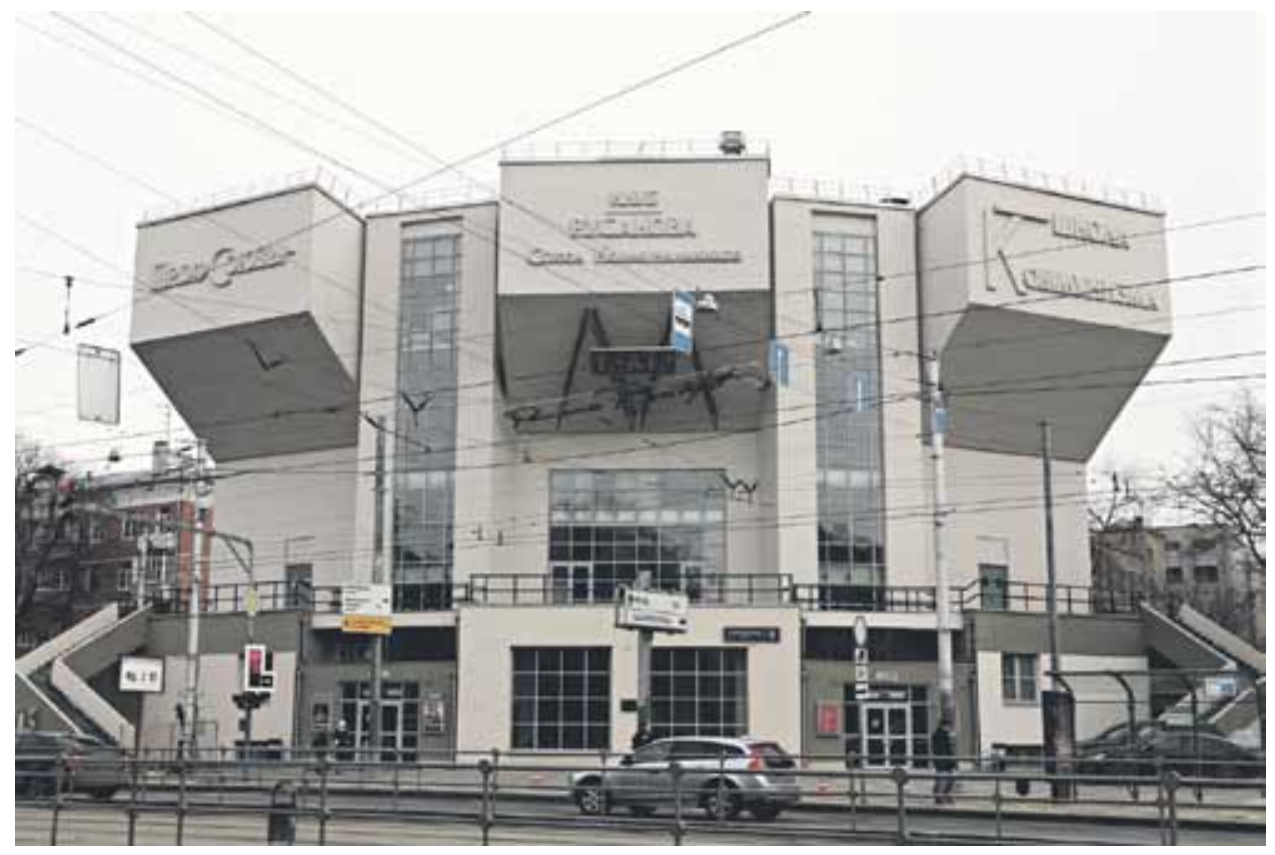

Rusakovin työläisten klubi (ulitsa Stromynka 6). Konstantin Melnikovin (1890-1974) vuonna 1927 suunnittelema kulttuuritalo ja klubi. Pääasiassa betonista ja lasista toteutetun rakennuksen tyylin oli määrä ilmentää lihasvoimaa. Seinän kolmen ulokkeen sisällä on erilliset katsomot, jotka on mahdollista yhdistää yhdeksi suureksi auditorioksi. Rakennus pääsi kurjaan kuntoon neuvostoaikana, mutta otettiin 1990-luvulla World Monuments Fundin tarkkailulistalle, jonka kautta entisöintiin saatiin tukea. Klubin tiloja käyttää nyt teatteri.

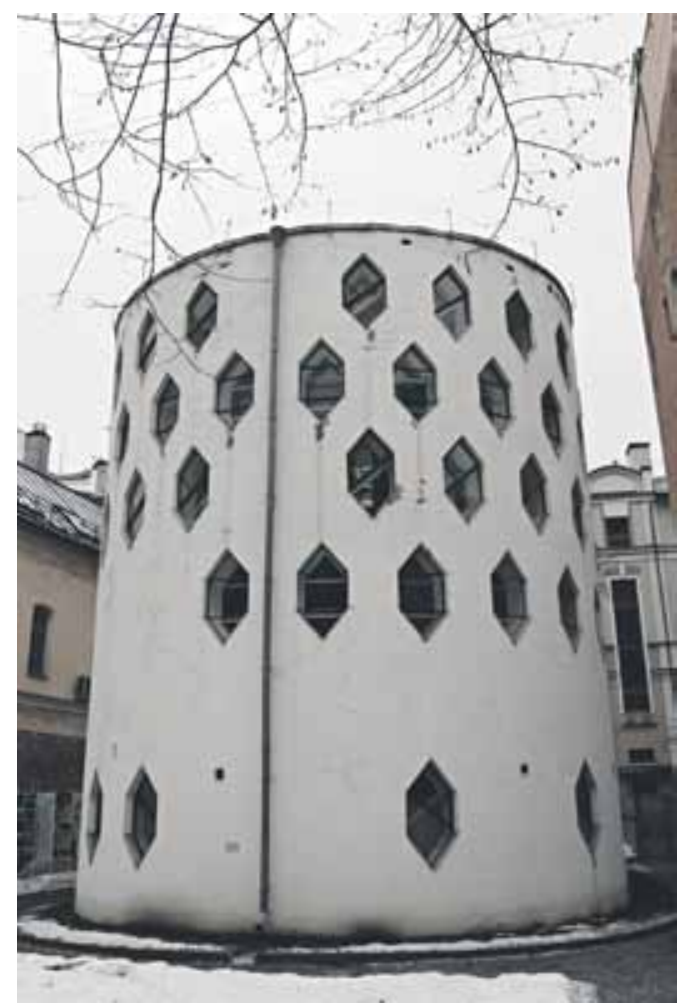

Melnikovin talo (ulitsa Olhovskaja 4). Arkkitehti Konstantin Melnikovin 1920-luvun lopulla itselleen suunnittelema koti. Rapattu pyöreä tiilirakennus muodostuu yli kahdestasadasta kennosta, joista osa on ikkunoita. Konstruktivismin kultakaudella Melnikovin taloa harkittiin jopa sarjatuotantoon, mutta se unohtui 1930-luvulla. Melnikov itse sai silti asua talossa Moskovan keskustassa läpi Stalinin valtakauden, vaikka tuomittiin "formalistiksi". Nykyään rakennus on museoitu ja sen pihassa on infotauluja sekä Melnikovin urasta että talon rakentamisesta. 


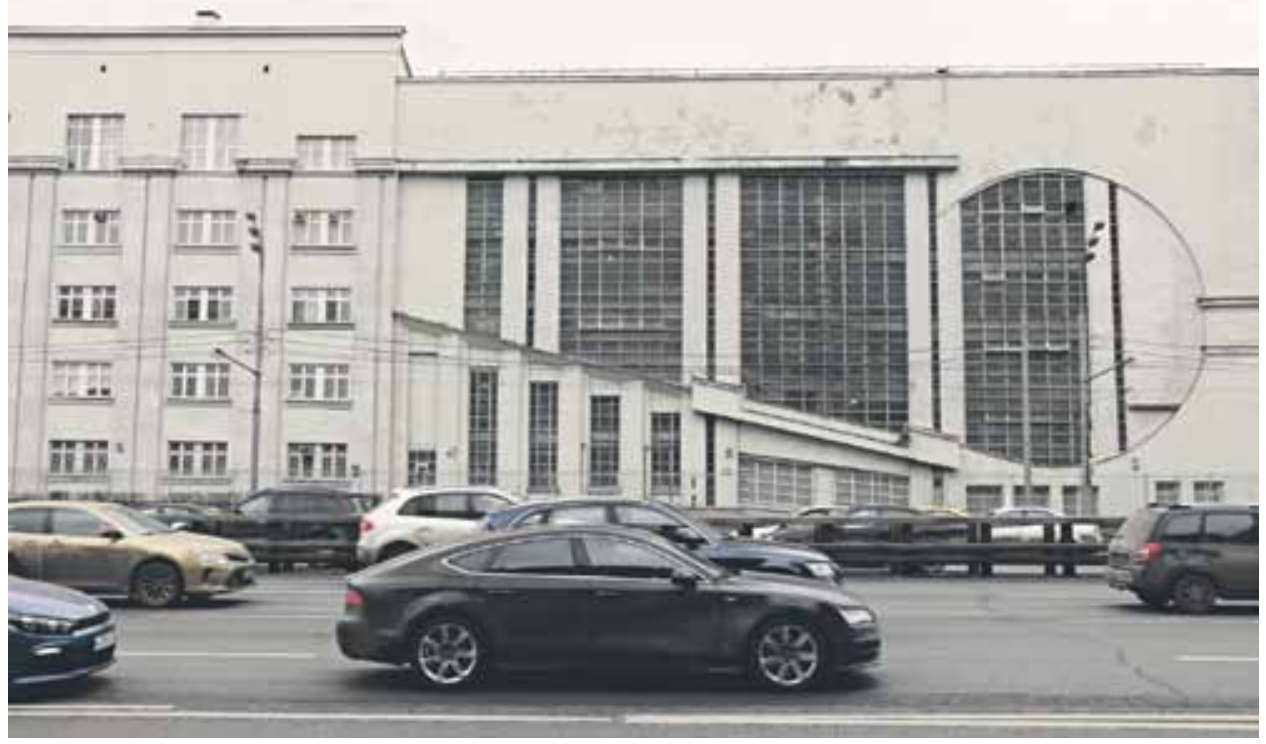

Intouristin autotalli (ulitsa Suštšovski Val 33). Lukuisia konstruktivistisia rakennuksia suunnitelleen Konstantin Melnikovin luomus toteutettiin 1930-luvulla uuden matkatoimisto Intouristin käyttöön. Suuressa rakennuksessa valoa antavan fasadin takana pidettiin Intouristin käyttämiä linja-autoja ja muita liikennevälineitä, viereisessä talossa oli toimistoja. Nykyään talli on purettu, mutta etuseinä on suojeltu ja jätetty paikalleen Moskovan Puutarhakehätien varteen.

Zujevin työläisten klubi (ulitsa Lesnaja 18). Arkkitehti Ilja Golosovin (18831945) työläisten tapaamis- ja harrastetilaksi 1920-luvun lopulla suunnittelema paikka. Suurehkon rakennuksen sisällä oli kirjasto-ja sanomalehtisalit, harrastehuoneita ja auditorio. Päätyseinän lasirakenteita muurattiin umpeen neuvostoaikaisten remonttien yhteydessä, mutta muuten muoto on säilynyt entisellään. Sylinterimäisessä lasiosassa kulkee portaikko. Rakennuksessa toimii nykyään teatteri.

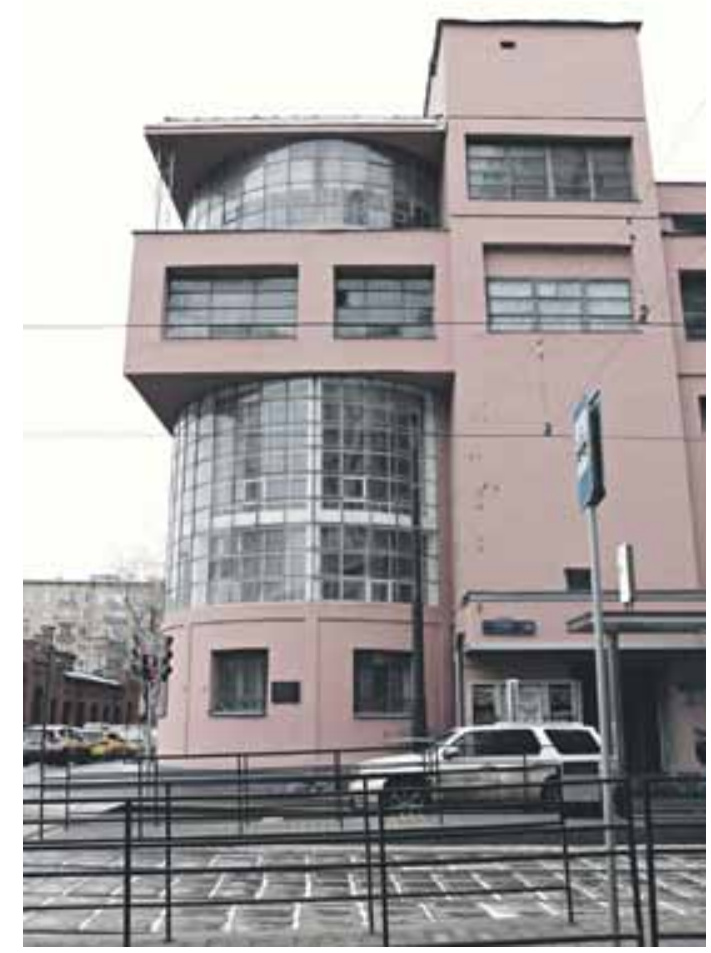




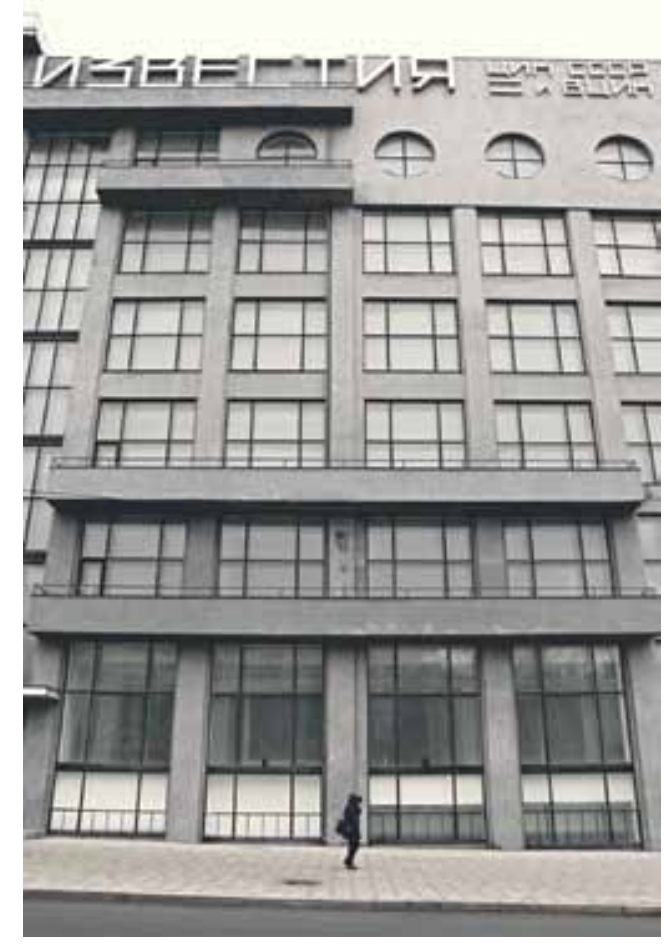

Izvestija-lehden pääkonttori (Puškinskaja plošad 5). Pietarin taideakatemiassa ennen vallankumousta opiskelleen ja Irkutskin kaupunginarkkitehtina toimineen Grigori Barhinin (1880-1969) tunnetuin luomus on sanomalehti Izvestijan toimitus ja paino vuodelta 1927. Puškinin aukion laidalla sijaitseva rakennus on teräsbetonirunkoinen ja edustaa virtaviivaista konstruktivistista tyyliä. Rakennusta jatkettiin 1970-luvulla massiivisella uudisosalla aukion reunan mukaisesti, mutta alkuperäinen säilyi. Vanha osa on nyt restauroitu alkuperäistä vastaavaan asuun.

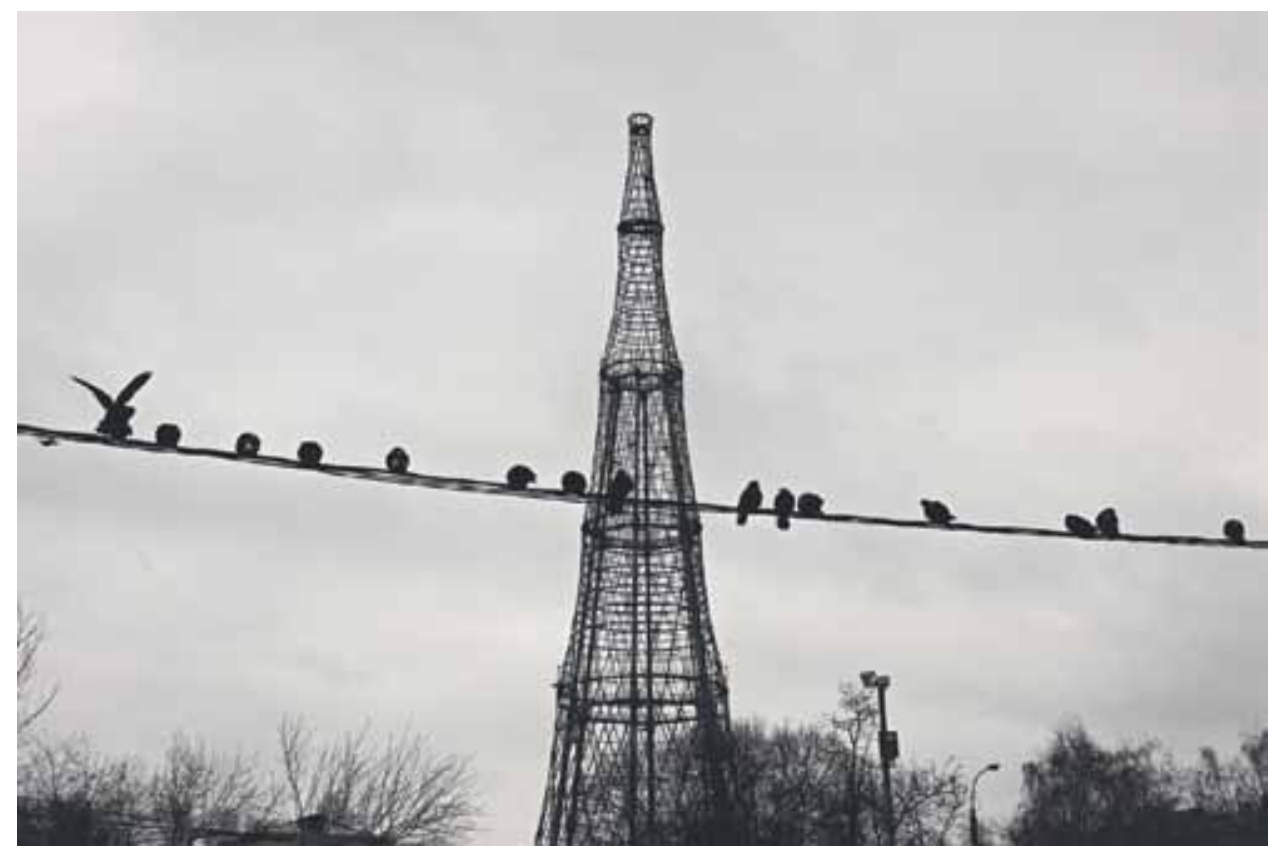

Šuhovin torni (ulitsa Šuhova 8). Venäjän keisarikunnan ajalla satoja siltoja suunnitellut Vladimir Šuhov (1853-1939) innostui 1920-luvun alussa konstruktivistisesta arkkitehtuurista. "Moskovan Eiffelin tornista" piti alun perin tulla viisitoista metriä Eiffeliä korkeampi, mutta metallipula madalsi 1922 valmistuneen tornin mitan puoleen. Siitä tuli silti aikansa tehokkain radiolähetystorni. Šuhovin suunnittelema ristikkorakenne säästi metallia ja teki rakennelmasta kevyen. Torni aiottiin joitain vuosia sitten purkaa huonokuntoisena, mutta saatiin suojeltua. 